\title{
Presence of additional P. vivax malaria in Duffy negative individuals from Southwestern Nigeria: Short Report
}

MARY Aigbiremo OBOH ( $\square$ aigbi4god@gmail.com )

Medical Research Council Unit The Gambia https://orcid.org/0000-0001-5720-8425

Upasana Shyamsunder Singh

School of Health and Environment, University of Manchester, United Kingdom

Daouda Ndiaye

Universite Cheikh Anta Diop Faculte de Medecine de Pharmacie et d'Odontologie

Aida Sadikh Badiane

Universite Cheikh Anta Diop Faculte de Medecine de Pharmacie et d'Odontologie

Nazia Anwar Ali

ICMR-National Institute of Research in Tribal Health

Praveen Kumar Bharti

ICMR-National Institute of Research in Tribal Health

Aparup Das

ICMR-National Institute of Research in Tribal Health

\section{Short report}

Keywords: sub-Saharan Africa, Duffy Antigen Receptor for Chemokines, Plasmodium vivax, mix-infection, genetic-epidemiology

Posted Date: March 4th, 2020

DOI: https://doi.org/10.21203/rs.3.rs-15945/v1

License: (c) (i) This work is licensed under a Creative Commons Attribution 4.0 International License. Read Full License 


\section{Abstract}

Background Malaria in sub-Saharan Africa (sSA) is thought to be hugely caused by Plasmodium falciparum. Recently, growing reports of cases due to P. ovale , P. malariae, and P. vivax have been significantly reported to play a role in malaria epidemiology in sSA. This in fact is due to the usage of very sensitive diagnostic tools (e.g. PCR) which have highlighted the underestimation of non-falciparum malaria in this sub-region. P. vivax was historically thought to be absent in sSA due to the high prevalence of the Duffy null antigen in individuals residing in this sub-continent. For example, recent studies reporting the detection of vivax malaria in Duffy-negative individuals from Mali, Mauritania, Cameroon to mention a few challenges this notion.

Methods Following our earlier report of P. vivax in Duffy-negative individuals, we have collected and assessed RDT and/or microscope malaria positive samples following the conventional PCR method and DNA sequencing to confirm both single/mixed infections as well as the Duffy status of the individuals.

Results Amplification of Plasmodium gDNA was possible in 59.9\% (145/242) of the evaluated isolates and as expected P. falciparum was the most predominant (91.7\%) species identified. Interestingly, four P. vivax isolates were identified either as single (3) or mixed (1 - P. falciparum / P. vivax ) infection. Sequencing results confirmed, all vivax isolates as truly vivax malaria and their Duffy status to be that of the Duffy-negative genotype.

Conclusion Identification of more vivax isolates among these Duffy-negative individuals from Nigeria, substantiate the expanding body of evidence on the ability of P. vivax to infect RBCs that do not express the DARC gene. Hence, such genetic-epidemiological study should be conducted at the national level in order to evaluate the actual burden of P. vivax in the country.

\section{Background}

Malaria is a critical infectious disease of public health importance that provokes considerable mortality in all endemic countries. The tremendous gains seen in cases and mortality reduction is as a result of deliberate intervention strategies [1]. However, the observed benefit has seen a plateau in the last two years especially in Africa where the greatest burden of disease is mostly impacted. In sub-Saharan Africa (sSA), majority (99\%) of the infections is thought to be due to Plasmodium falciparum and rarely by P. ovale, P. malariae, with P. vivax not even being considered in the picture as one of the players [1] of malaria infection. With the availability of tools that are more sensitive, the detection of non-falciparum and even vivax human malaria parasites has gained more attention in SSA [2-6].

Historically, P. vivax prevails in Asia, [7, 8], South America [9, 10] and has some scanty presence in the Horns of Africa such as in Djibouti [11], Eritrea [12], Somalia $[13,14]$, Ethiopia [15-18] and Sudan $[19,20]$. Thus P. vivax has a much wider geographical distribution unlike falciparum malaria which in a more specific term, can be said to have a much focal distribution in Africa.

Hence, the former notion is that, P. vivax originates from Asia and South America and gradually finds its way into Africa through the trade-route corridor. However, there are some current evidences supporting the hypothesis that, P. vivax could have originally evolved from a vivax-like strain detected in nonhuman primates in Africa [21, 22] and from there, dispersed to other continents during the period of human migration. Although, both hypotheses (whether from Africa to Asia or, Asia to Africa) require further validation. However, it seems likely that there might be an interplay of both hypothesis, in which case, simultaneous occurrence takes place and selective adaptation of the Duffy negative allele in sSA might have resulted in the absence of vivax malaria in the region. Nonetheless, later re-introduced when individuals expressing the Duffy null allele travels between continents and countries.

The Duffy (gp-FY; CD234) gene is the fourth red blood cell (RBC) gene after thalassemia, sickle cell anaemia and glucose-6-phosphate dehydrogenase (G6PD) associated with resistance to Plasmodium species [23] with particular protection against vivax malaria. Also known as the Duffy antigen receptor for chemokines (DARC), it is a variable receptor usually expressed on the surface of the red blood cell (RBC) and employed by P. vivax merozoites in gaining access in the RBCs and establishing its erythrocytic infection [24]. The DARC, located on chromosome 1 has two exons, and a single nucleotide substitution from a thymine $(T)$ to a cytosine $(C)$, upstream in the promoter region nullifies the expression of this gene on the RBCs, resulting in the FYO* allele [25]. This FYO* null allele predominates amongst SSA inhabitants as with African-Americans but has a very sparse representation in individuals of other ancestry [26]. Thus, the FYO* null allele has been validated to confer protection against $\mathrm{P}$. vivax infection in this sub-region. Nevertheless, 11 countries in this region (Oboh et al unpublished data) have reported the occurrence of P. vivax, making it more real that vivax malaria might be gradually finding its way into sSA, thus it can be postulated that hidden transmission is occurring in this region. In some of these studies, such as in those conducted in Angola, Cameroon, Kenya, Madagascar, Mali and Mauritania, the Duffy status of the infected individuals was characterized and they were found to be mostly Duffy negative [3, 4, 2730]. In others, however, the investigators were concerned with the identification of P. vivax without stating the Duffy status of the infected individuals [5, 3133]. Interestingly, all studies were carried out amongst indigenous individuals with little or no travel history to vivax endemic areas, thus ruling out the possibility of imported infection.

In Nigeria, P. falciparum is responsible for $>95 \%$ of malaria infection, with P. malariae and P. ovale contributing a meagre $<5 \%$ of infection [1, 34]. Data implicating P. vivax infection in Nigeria includes its detection in a visiting pregnant female [35], two cases detected by microscopy [36, 37], both of which were not confirmed by any molecular technique and our previous study [6] which detected five Duffy negative individuals to be infected with P. vivax isolates and were subsequently confirmed by capillary sequencing.

Thus, as a follow-up to our previous study, we have collected samples from two sites - Oredo and Kosofe in Edo and Lagos state respectively and used the classical PCR method, to confirm additional P. vivax isolates (both single and mixed infection) by sequencing, as well as determined the Duffy status of the individuals. The importance of such genomic epidemiological studies cannot be undermined in this era of malaria elimination, as attention also needs to be given to non-falciparum infection, if the ambitious albeit, achievable 2030 elimination goal is to be reached. 


\section{Methods}

Blood samples were collected from symptomatic patients attending two hospitals in Lagos (Gbagada) and Edo (Central) states respectively between December 2016- January 2017. Samples were quickly subjected to malaria rapid diagnostic test kit, employing the manufacturer's instruction (Pf-HRPII- Care Start ${ }^{\circledR}$, Access Bio Inc, Batch number M014L04-M014M10) followed by microscopy. Two dried blood-spots per patient (436 in total), irrespective of their status (positive or negative by any of the techniques above) were made on Whatmann ${ }^{\circledR}$ (GE Healthcare, Life Sciences) filter paper and brought to the ICMRNational Institute of Research in Tribal Health (ICMR-NIRTH), Jabalpur, India.

Employing the Qiagen ${ }^{\circledR}$ kit (the QIAamp DNA Blood Mini Kit; Hilden, Germany), genomic DNA was isolated from all 242 samples and subsequently subjected to nested PCR diagnostic protocol targeting the 18S rRNA to identify all four Plasmodium infecting species using primer pairs as designed earlier [38]. For each PCR run, a negative control (nuclease free water) and positive controls (sequenced confirmed Plasmodium species-for all four species) were added. In addition, a part of the promoter region of Duffy gene (for isolates that are P. vivax positive) was PCR amplified and sequenced in order to determine their Duffy status using protocols and primer sequence detailed in our previous work [6].

Representative isolates of Plasmodium species (P. falciparum, P. vivax, P. malariae and P. ovale) were purified (using Fast ${ }^{A P}$ alkaline phosphatase and exonuclease I) and processed for sequencing by Sanger method (an in-house facility of ICMR-NIRTH, Jabalpur) in both direction (2X). Sequencing was performed on the purified PCR products in a volume of $10 \mu \mathrm{l}$ with $0.5 \mu \mathrm{l}$ of Terminator ready reaction mix (TRR), $1.6 \mathrm{pmol}$ of gene specific primer and $5 \mathrm{X}$ reaction buffer with a cycling condition of $96^{\circ} \mathrm{C}$ denaturation for 10 secs $\left(25\right.$ cycles), annealing at $50{ }^{\circ} \mathrm{C}$ for 5 sec and an extension of $60{ }^{\circ} \mathrm{C}$ for four minutes. Base calling of nucleotide and chromatogram visualization was achieved with the use of the sequence analysis software accompanying the DNA analyzer, while sequence alignment was carried out using BioEdit sequence alignment editor v.7.0.5.3. Contiguous sequences were aligned with their respective reference strains (P. vivax -SAL-1 accession number U03079.1; P. falciparum-3D7 accession umber XR_002273095.1; P. ovale- accession number L48987.1; P. malariae- accession number NG_011626.30 and, the Duffy gene; accession number NG_011626.30).

\section{Results And Discussions}

Between December 2016 and January 2017, we were able to collect a total of two hundred and forty-two samples from both study areas, with majority of the samples (171) being from Oredo in Edo State. The mean age group from both localities are almost the same, 25 years in Kosofe and 26 years in Oredo. As with the mean age, the ratio of male to female is almost same (1:1.2) Table 1.

Table 1: Background information of the study participants

\begin{tabular}{llll}
\hline & Kosofe & Oredo & Total \\
\hline Number & 71 & 171 & 242 \\
Percentage (\%) & 29.3 & 70.7 & 100 \\
\hline Age & & & \\
\hline Mean & 25 & 26 & \\
$\quad$ Range & $2-85$ & $2-86$ & \\
\hline Sex & & & \\
\hline Male & 36 & 73 & 109 \\
\hline Female & 35 & 98 & 133 \\
\hline
\end{tabular}

All 242 samples were subjected to the three diagnostic tools- RDT, microscopy and PCR and the outcome were widely differential. Whilst RDT (187) and PCR (145) gave the highest positive results, that of microscopy was abysmally poor detecting only 53 positive isolates. Thus, using PCR as the gold standard RDT gave a higher sensitivity (84.8\%), although with a low specificity (34\%). On the other hand, the specificity of microscopy was remarkably higher (82.5\%) than what was obtained in RDT.

However, a converse pattern was noticed with regards to the likelihood of a positive or negative sample being correctly identified as such. For RDT, the chances of a positive samples turning out positive by PCR- positive predictive value (PPV) was lower (65.8\%) than what was observed with microscopy (67.9\%) while the chances of it being picked as truly negative; negative predictive value (NPV) was high (60\%) Table 2.

Table 2: Diagnostic performance of the different tools

\begin{tabular}{cllllllll}
\hline \multicolumn{2}{c}{ PCR } & & Sensitivity & Specificity & PPV & NPV & Kappa's Test & P-value \\
\hline $\begin{array}{c}\text { Microscopy } \\
\text { Positive }\end{array}$ & Negative & & & & & & \\
\hline Positive & 36 & 17 & 24.8 & 82.5 & 67.9 & 42.3 & 0.063 & 0.18 \\
\hline Negative & 109 & 80 & & & & & & \\
\hline RDT & & & & & & & & \\
\hline $\begin{array}{c}\text { Positive } \\
\text { Negative }\end{array}$ & 123 & 64 & 84.8 & 34.0 & 65.8 & 60.0 & 0.203 & 0.01 \\
\hline
\end{tabular}


As explained, Plasmodium genomic DNA was amplifiable in $59.9 \%(145 / 242)$ of the isolates. As expected, $P$. falciparum was the most abundant malaria species detected in both localities (106 in Oredo and 27 in Kosofe). The occurrence of other species in both states were rare either in single ( $P$. malariae - $1, P$. ovale -1, P. vivax -3 ) or mixed (P. ovale /falciparum - 6, P. falciparum/ P. vivax -1$)$ infections Fig. 1

The gDNA of the identified P. vivax isolates were re-extracted and amplified twice following our earlier [6] protocol in order to be sure of their status. Gel documentation of all newly identified isolates is presented in Fig. 2.

Authentication of the PCR results were followed by sequencing (in the forward and reverse direction) the 18S rRNA of the identified $P$. vivax and representative of other species. Sequences were edited and aligned (using BioEdit) with their respective reference strain: $P$. vivax with the Sal-1 strain (accession number U03079.1), $P$. falciparum with the 3D7 strain (accession umber XR_002273095.1), P. ovale (accession number L48987.1) and $P$. malariae (accession number NG_011626.30). Surprisingly, all sequences showed perfect homology (100\% similarity) with their references as expected (Fig. 3 - for $P$. vivax). This is not unexpected as cases of $P$. vivax have been identified in many countries in SSA [3-5, 29, 33, 39-42] including Nigeria [6], where it was thought to be absent due to the non-expression of the DARC gene on the RBC of majority of the population.Thus, this is adding to the growing evidence of the proposed gradual incursion of $P$. vivax into SSA sub-region.

In order to discern the Duffy status of those $P$. vivax infected patients, a portion of the DARC gene (precisely the promoter region covering the T33C point mutation) was amplified and sequenced follwing previous protocol [43]. Unanticipatedly, all four additional $P$. vivax isolates carried a single cytosine (C) peak at the $33^{\text {rd }}$ nucleotide position upstream (Fig. 4). Thus, confirming that none of them expressed the Duffy gene on their RBCs and as such are Duffy negative.

The identification of more $P$. vivax isolates among these Duffy-negative individuals from Nigeria, substantiate the expanding body of evidence of the ability of $P$. vivax to infect RBCs that do not express the DARC gene. Although a very recent findings point to another receptor on the reticulocyte- transferrin receptor 1 as a specific $P$. vivax receptor [44], which is being proposed to be an alternate route of entry into the RBCs, this however is subject to further verification. The above hypothesis is one of the proposition being made to support the observation of $P$. vivax in sSA [45]. Another which relies on the first conjecture (assuming it is agreed that $P$. vivax at least possesses alternative invasion pathway), is that the Duffy positive carriers in northern part of Africa and the AfroAsiatic populations of Sudan, Somalia $[20,46]$ and Ethiopia $[47,48]$ serve as reservoir to effect transmission to Duffy negative individuals in those areas as well as other countries (in SSA) through migration. Albeit, this particular hypothesis at play here is yet to be determined. One thing is clear here however, that the true epidemiological situation of $P$. vivax in SSA in particular and Africa in general is yet to be ascertained.

\section{Conclusion}

It is pertinent to carry out more genetic-epidemiological studies in other areas (for example this study covers only two states out of the thirty-six in Nigeria) of the country as with other SSA countries. This will aid in putting in place appropriate control strategies to combat the menace of malaria infection in this most affected population (Africa) and also prevent further spread of P. vivax in Africa.

\section{Abbreviations}

SSA

sub-Saharan Africa

PCR

Polymerase Chain Reaction

DARC

Duffy Antigen Receptor for Chemokines

RBC

Red Blood Cell

G6PD

Glucose-6-Phosphate Dehydrogenase Deficiency

TRR

Terminator Ready Reaction Mix

RDT

Rapid Diagnostic Test

PPV

Positive Predictive Value

NPV

Negative Predictive Value

\section{Declarations}

\section{Ethical approval and consent for publication}

Approval (IRB/16/347) for this study was obtained from the Institutional Review Board of the Nigerian Institute of Medical research.

\section{Consent for publication}


Not applicable

\section{Availability of data}

The datasets generated in this study are included in the manuscript except the sequences which will be submitted to Genbank (......) and acession made availble.

\section{Competing interest}

The authors declare that they have no competing interests.

\section{Funding}

This work was graciously funded by the Department of Science and Technology, and Ministry of External Affairs (MEA), Government of India (Gol), and the Federation of Indian Chambers of Commerce and Industry (FICCI) for awarding the Visiting Fellowship under the CV Raman Fellowship scheme.

\section{Authors contribution}

MAO and AD conceptualised and designed the study. MAO, NZ and PKB carried out laboratory analysis. MAO analysed data. MAO and Ad wrote manuscript with inputs from the other authors.

All authors read and approved the work

\section{Acknowledgements}

We thank all the study participants for consenting to donate blood samples for this study. Thanks are also due to the Rector of the Université Cheikh Anta Diop de Dakar, Senegal and Director of ICMR - National Institute of Research in Tribal Health (NIRTH) for providing instrumental facilities. We thank Mrs. Ayanlere, Central Hospital, Nigeria, and Mr. Agbayewa, Ikate Primary Health Care, Nigeria for helping in the collection of samples and Mr. Sri Krishna and Ms. Priyanka Patel, ICMR-NIRTH, India for assistance in the laboratory.

\section{References}

1. WHO. WMR. 2018.

2. Daniels RF, Deme AB, Gomis JF, Dieye B, Durfee K, Thwing JI, et al. Evidence of non-Plasmodium falciparum malaria infection in Kédougou, Sénégal. Malar J. 2017;16:9.

3. Mbenda HGN, Das A. Molecular evidence of plasmodium vivax mono and mixed malaria parasite infections in duffy-negative native cameroonians. PLoS One. 2014;9:e103262.

4. Fru-Cho J, Bumah V V., Safeukui I, Nkuo-Akenji T, Titanji VPK, Haldar K. Molecular typing reveals substantial Plasmodium vivax infection in asymptomatic adults in a rural area of Cameroon. Malar J. 2014;13:170.

5. Niang M, Diop F, Niang O, Sadio BD, Sow A, Faye O, et al. Unexpected high circulation of Plasmodium vivax in asymptomatic children from Kédougou, southeastern Senegal. Malar J. 2017;16:497. doi:10.1186/s12936-017-2146-8.

6. Oboh MA, Badiane AS, Ntadom G, Ndiaye YD, Diongue K. Molecular identification of Plasmodium species responsible for malaria reveals Plasmodium vivax isolates in Duffy negative individuals from southwestern Nigeria. Malar J. 2018;17:439. doi:10.1186/s12936-018-2588-7.

7. Gupta B, Gupta P, Sharma A, Singh V, Dash AP, Das A. High proportion of mixed-species Plasmodium infections in India revealed by PCR diagnostic assay. Trop Med Int Heal. 2010;15:819-24.

8. Steenkeste N, Rogers WO, Okell L, Jeanne I, Incardona S, Duval L, et al. Sub-microscopic malaria cases and mixed malaria infection in a remote area of high malaria endemicity in Rattanakiri province, Cambodia: Implication for malaria elimination. Malar J. 2010;9:108.

9. Trouvay M, Palazon G, Berger F, Volney B, Blanchet D, Faway E, et al. High Performance of Histidine-Rich Protein 2 Based Rapid Diagnostic Tests in French Guiana are Explained by the Absence of pfhrp2 Gene Deletion in P. falciparum. PLoS One. 2013;8:e74269.

10. Genton B, D'Acremont V, Rare L, Baea K, Reeder JC, Alpers MP, et al. Plasmodium vivax and mixed infections are associated with severe malaria in children: A prospective cohort study from Papua New Guinea. PLoS Med. 2008;5:e127.

11. Khaireh BA, Briolant S, Pascual A, Mokrane M, Machault V, Travaill C, et al. Plasmodium vivax and Plasmodium falciparum in the Republic of Djobouti: evaluation of their prevalence and potential determinants. Malar J. 2012;11:395.

12. Roggelin L, Tappe D, Noack B, Addo MM, Tannich E, Rothe C. Sharp increase of imported Plasmodium vivax malaria seen in migrants from Eritrea in Hamburg, Germany. Malar J. 2016;15:325.

13. Smoak BL, DeFraites RF, Magill AJ, Kain KC, Wellde BT. Plasmodium vivax infections in U.S. Army troops: Failure of primaquine to prevent relapse in studies from Somalia. Am J Trop Med Hyg. 1997;56:231-4.

14. Heppner DG, Magill AJ, Gasser RA, N OC. Infectious diseases in Somalia. N Engl J Med. 1993;:987-94.

15. Mekonnen SK, Aseffa A, Medhin G, Berhe N, Velavan TP. Re-evaluation of microscopy confirmed Plasmodium falciparum and Plasmodium vivax malaria by nested PCR detection in southern Ethiopia. Malar J. 2014;13:48. doi:10.1186/1475-2875-13-48. 
16. Tadesse FG, Pett H, Baidjoe A, Lanke K, Grignard L, Sutherland C, et al. Submicroscopic carriage of Plasmodium falciparum and Plasmodium vivax in a low endemic area in Ethiopia where no parasitaemia was detected by microscopy or rapid diagnostic test. Malar J. 2015;14:303.

17. Seyoum D, Yewhalaw D, Duchateau L, Brandt P, Rosas-Aguirre A, Speybroeck N. Household level spatio-temporal analysis of Plasmodium falciparum and Plasmodium vivax malaria in Ethiopia. Parasit Vectors. 2017;10:196. doi:10.1186/s13071-017-2124-6.

18. Nigatu W, Abebe M, Dejene A. Plasmodium vivax and P. falciparum epidemiology in Gambella, south-west Ethiopia. Trop Med Parasitol. 1992;43:181-5. http://www.ncbi.nlm.nih.gov/pubmed/1470839.

19. Mahgoub H, Gasim GI, Musa IR, Adam I. Severe Plasmodium vivax malaria among sudanese children at New Halfa Hospital, Eastern Sudan. Parasites and Vectors. 2012;5:154. doi:10.1186/1756-3305-5-154.

20. Abdelraheem MH, Albsheer MMA, Mohamed HS, Amin M, Hamid MMA. Transmission of Plasmodium vivax in Duffy-negative individuals in central Sudan. Trans R Soc Trop Med Hyg. 2016;110:258-60.

21. Culleton R, Carter R. African Plasmodium vivax: Distribution and origins. Int J Parasitol. 2012;42:1091-7. doi:10.1016/j.ijpara.2012.08.005.

22. Loy DE, Plenderleith LJ, Sundararaman SA, Liu W, Gruszczyk J, Chen Y-J, et al. Evolutionary history of human Plasmodium vivax revealed by genomewide analyses of related ape parasites. Proc Natl Acad Sci. 2018;:1-10. doi:10.1073/pnas.1810053115.

23. Miller LH, Mason SJ, Clyde DF, McGinniss MH. The Resistance Factor to Plasmodium vivax in Blacks. N Engl J Med. 1976;295:302-4. doi:10.1056/NEJM197608052950602.

24. Carvalho GB de, Carvalho GB de. Duffy blood group system and the malaria adaptation process in humans. Rev Bras Hematol Hemoter. 2011;33:55-64. doi:10.5581/1516-8484.20110016.

25. Tournamille C, Colin Y, Cartron JP, Kim CL Van. Disruption of a GATA motif in the Duffy gene promoter abolishes erythroid gene expression in Duffynegative individuals. Nat Genet. 1995;10:196-201.

26. Reid ME, Lomas-Francis C. The blood group antigen Factbook. Elsevier Academic Press; 2004. doi:10.1007/s13398-014-0173-7.2.

27. Ménard D, Barnadas C, Bouchier C, Henry-halldin C, Gray LR. Plasmodium vivax clinical malaria is commonly observed in Duffy-negative Malagasy people. Proc Natl Acad Sci. 2010;107:5967-71.

28. Mendes C, Dias F, Figueiredo J, Mora VG, Cano J, de Sousa B, et al. Duffy negative antigen is no longer a barrier to Plasmodium vivax - molecular evidences from the African West Coast (Angola and Equatorial Guinea). PLoS Negl Trop Dis. 2011;5:e1192.

29. Niangaly A, Gunalan K, Ouattara A, Coulibaly D, Juliana MS, Adams M, et al. Plasmodium vivax Infections over 3 Years in Duffy Blood Group Negative Malians in Bandiagara, Mali. Am J Trop Med Hyg. 2017;97:744-52.

30. Ryan JR, Stoute JA, Amon J, Dunton RF, Mtalib R, Koros J, et al. Evidence for transmission of Plasmodium vivax among a Duffy antigen negative population in Western Kenya. Am J Trop Med Hyg. 2006;75:575-81.

31. Culleton R, Ndounga M, Zeyrek FY, Coban C, Casimiro PN, Takeo S, et al. Evidence for the Transmission of Plasmodium vivax in the Republic of the Congo, West Central Africa. J Infect Dis. 2009;200:1465-9. doi:10.1086/644510.

32. Guerra-neira A, Rubio JM, Royo JR, Ortega JC, Auñón AS, Diaz PB, et al. Plasmodium diversity in non-malaria individuals from the Bioko Island in Equatorial Guinea (West Central-Africa ). Int J Health Geogr. 2006;5:27.

33. Niang M, Thiam LG, Sow A, Loucoubar C, Bob NS, Diop F, et al. A molecular survey of acute febrile illnesses reveals Plasmodium vivax infections in Kedougou, southeastern Senegal. Malar J. 2015;14:281.

34. FMoH. National Malaria Indicator Survey. 2015.

35. Graffeo R, Masucci L, Bugli F, Damiano F, Pinnetti C, Federico G, et al. Multiple malaria infection in a pregnant woman from Nigeria: Detection by multiplex PCR. New Microbiol. 2008;31:565-7.

36. Babamale, OA and UU. Status of Malaria Infection in Peri-Urban Community of North Central Region of Nigeria. J Bacteriol Parasitol. 2016;7:1-6.

37. Erhabor O, Babatunde S, Uko KE. Some haematological parameters in plasmodial parasitized HIV-infected Nigerians . Niger J Med. 2006;15:52-5.

38. Snounou G, Viriyakosol S, Zhu P, Jarra W, Pinheiro L, Rosario V Do, et al. High sensitivity of detection of human malaria parasites by the use of nested polymerase chain reaction higher sensitivity of detection of these four Plasmodium. Mol Biochem Parasitol. 1993;61:315-20.

http://www.researchgate.net/publication/14934027_High_sensitivity_of_detection_of_human_malaria_parasites_by_the_use_of_nested_polymerase_chair

39. Poirier P, Doderer-Lang C, Atchade PS, Lemoine J-P, de l'Isle M-LC, Abou-bacar A, et al. The hide and seek of Plasmodium vivax in West Africa: report from a large-scale study in Beninese asymptomatic subjects. Malar J. 2016;15:570. doi:10.1186/s12936-016-1620-z.

40. Bernabeu M, Gomez-Perez GP, Sissoko S, Niambélé MB, Haibala AA, Sanz A, et al. Plasmodium vivax malaria in Mali: A study from three different regions. Malar J. 2012;11:405

41. Salem M, Ahmedou O, Lekweiry KM, Deida JM, Emouh AO, Weddady MO, et al. Increasing Prevalence of Plasmodium vivax among Febrile Patients in Nouakchott, Mauritania. Am J Trop Med Hyg. 2015;92:537-40.

42. Ba H, Duffy CW, Ahouidi AD, Deh YB, Diallo MY, Tandia A, et al. Widespread distribution of Plasmodium vivax malaria in Mauritania on the interface of the Maghreb and West Africa. Malar J. 2016;15:80.

43. Chittoria A, Mohanty S, Jaiswal YK, Das A. Natural Selection Mediated Association of the Duffy (FY) Gene Polymorphisms with Plasmodium vivax Malaria in India. PLoS One. 2012;7:e45219.

44. Gruszczyk J, Kanjee U, Chan LJ, Menant S, Malleret B, Lim NTY, et al. Transferrin receptor 1 is a reticulocyte-specific receptor for Plasmodium vivax. Science (80- ). 2018;359:48-55. 
45. Imwong M, Sudimack D, Pukrittayakamee S, Osorio L, Carlton JM, Day NPJ, et al. Microsatellite variation, repeat array length, and population history of Plasmodium vivax. Mol Biol Evol. 2006;23:1016-8.

46. Dalgleish T, Williams JMG., Golden A-MJ, Perkins N, Barrett LF, Barnard PJ, et al. Dsitribution of blood groups in the east African Somali Population. J Exp Psychol Gen. 2007;136:23-42.

47. Lo E, Yewhalaw D, Zhong D, Zemene E, Degefa T, Tushune K, et al. Molecular epidemiology of Plasmodium vivax and Plasmodium falciparum malaria among duffy-positive and Duffy-negative populations in Ethiopia. Malar J. 2015;14:84.

48. Mathews HM, Armstrong JC. Duffy blood types and vivax malaria in Ethiopia. Am J Trop Med Hyg. 1981;30:299-303.

\section{Figures}

\section{A: Oredo}

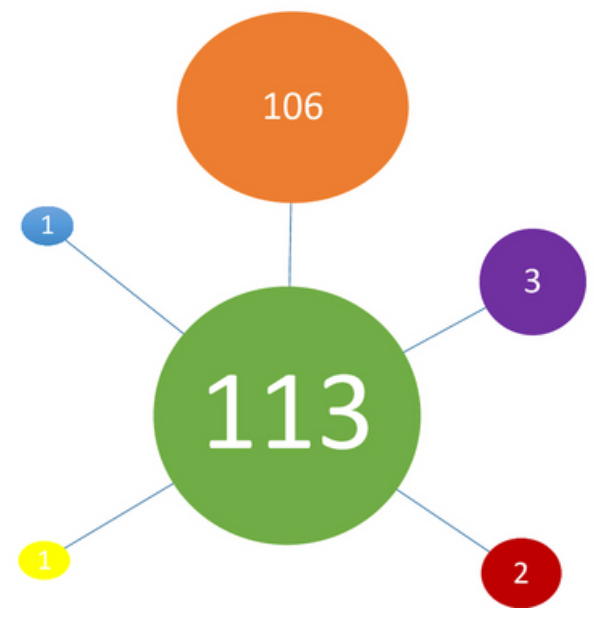

Figure 1

Proportional dynamics of Plasmodium species in both study locations

\section{B: Kosofe}

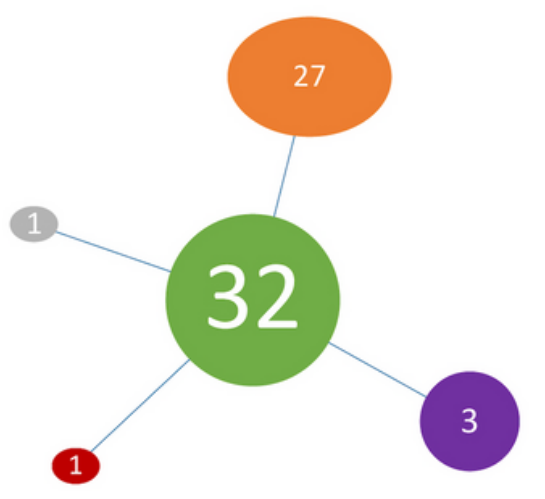

Plasmodium amplifiable gDNA

P. falciparum

P. ovale/P. falciparum

P. vivax

P. malariae

P. ovale

P. falciparum/P. vivax 


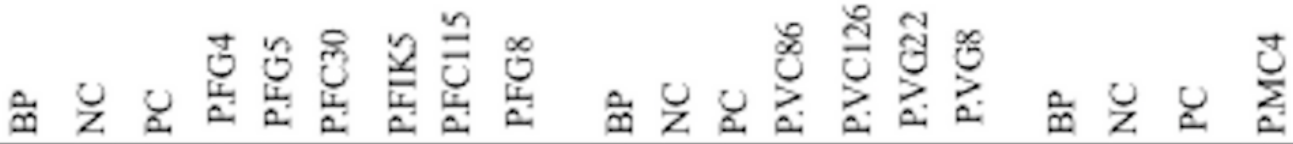

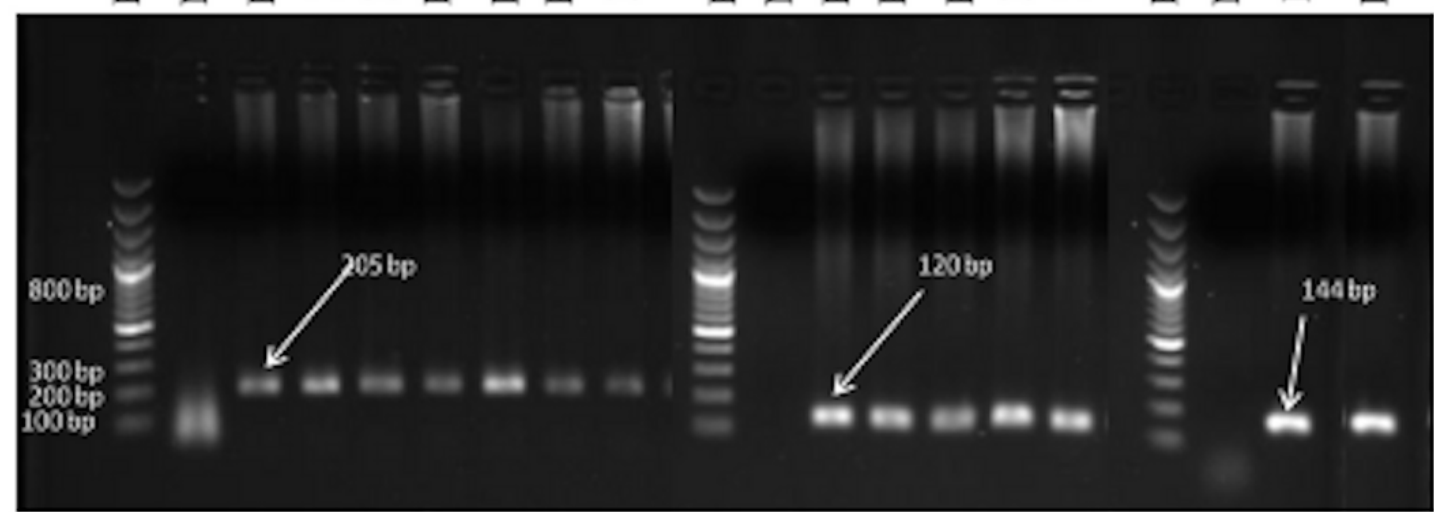

A

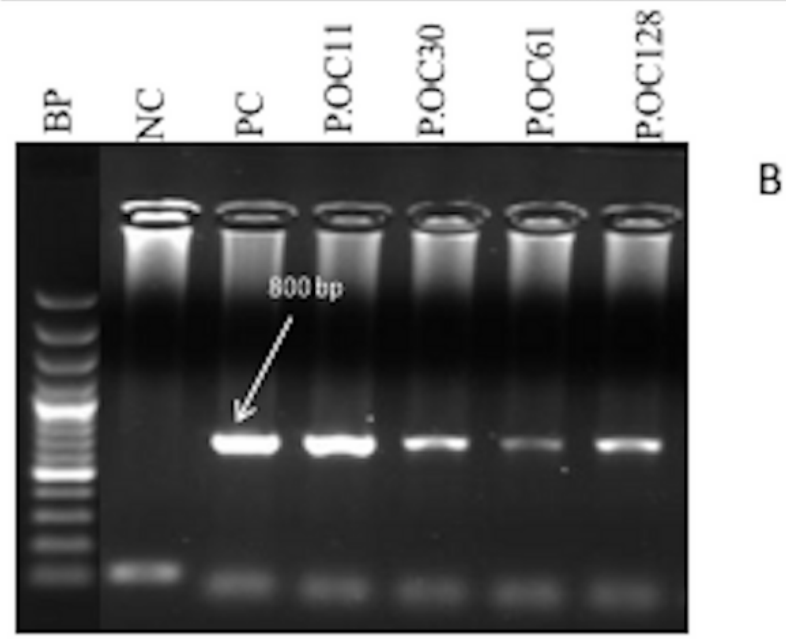

Figure 2

Gel documentation of various Plasmodium species. A-: First well - DNA base pair ladder, well 2: NC- negative control template (distill water), well 3- PC-P. falciparum positive control, well 4-9- isolates of P. falciparum, well 10- DNA base pair ladder, wells 11 and 12- negative and positive controls of P. vivax, wells 13-16- P. vivax samples, well 17- DNA base pair ladder, 18 and 19- negative and positive controls of P. malariae, well 20- the only additional P. malariae detected. B-: well 1- DNA base pair ladder, wells 2 and 3- negative and positive controls of P. ovale, wells 4-7- P. ovale isolates

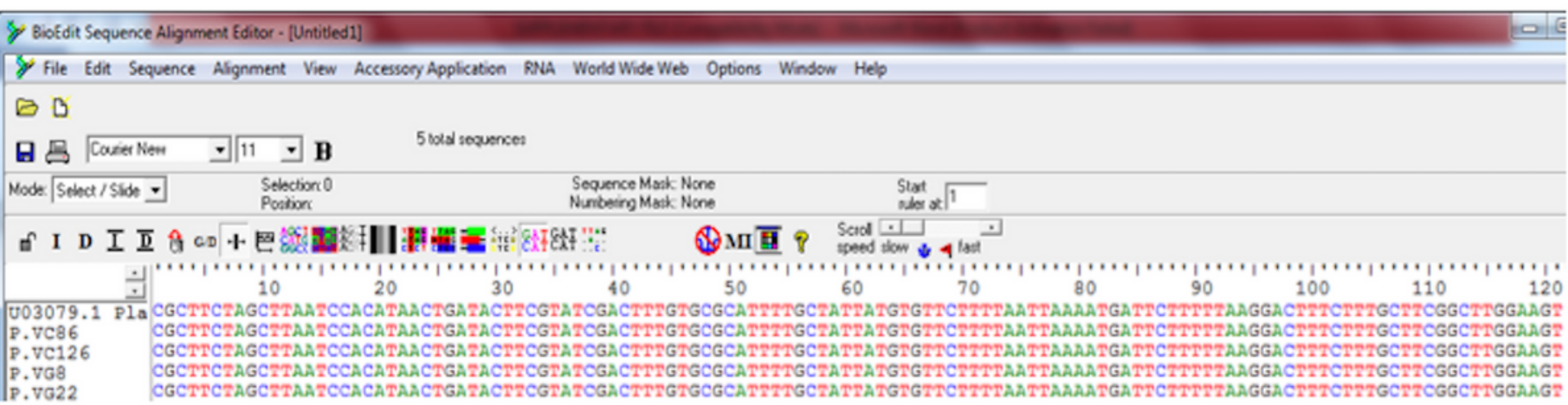

\section{Figure 3}

Multiple sequence alignment of P. vivax isolates and its Sal -1 reference sequence 

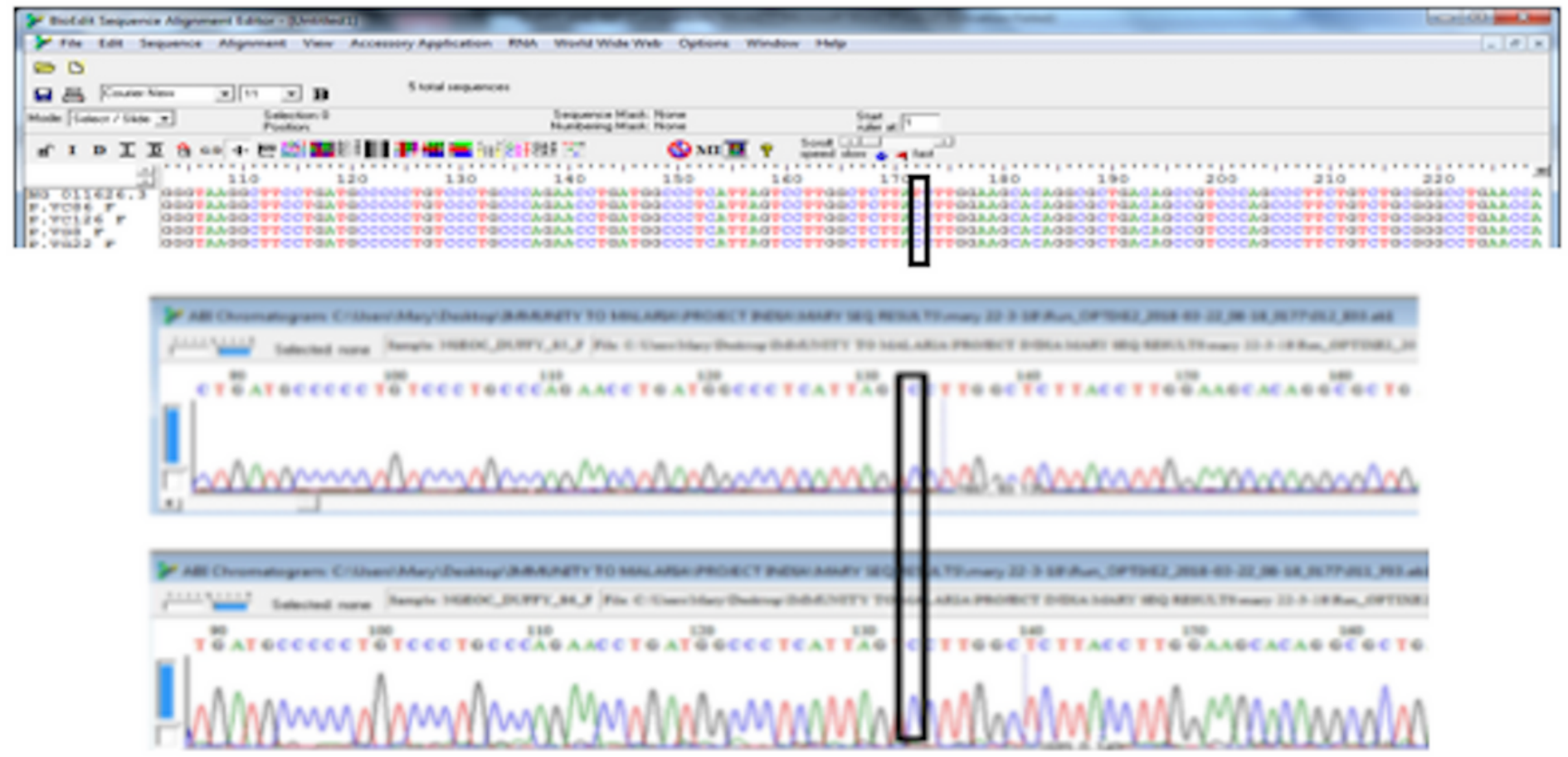

\section{Figure 4}

Multiple sequence alignment of the Duffy gene of the vivax samples displaying the -T33C nucleotide change which validates their Duffy negative status

\section{Supplementary Files}

This is a list of supplementary files associated with this preprint. Click to download.

- Figureforgraphicalabstract.tiff

- Figureforgraphicalabstract.tiff 